\title{
AVALIAÇÃO DA INFILTRAÇÃO BACTERIANA EM TÉCNICAS DE OBTURAÇÃO DO CANAL RADICULAR
}

\author{
EVALUATION OF BACTERIAL LEAKAGE IN TECHNIQUES OF ROOT CANAL \\ OBTURATION
}

\author{
Diego Leandro Ito* \\ Danilo Minor Shimabuko** \\ Carmo Antonio Aun *** \\ Thiago Bulhões Brum*...
}

\begin{abstract}
RESUMO
Introdução: Levando em consideração a necessidade de que o selamento do sistema de canais é um fator decisivo para o sucesso da terapia endodôntica, o presente estudo tem como objetivo avaliar a infiltração em dentes obturados com três técnicas de obturação: condensação lateral e vertical a frio, onda contínua de condensação aquecida (E \& Q Plus) e cone único (sistema Protaper Universal®). Métodos: Quarenta e oito dentes tiveram seu comprimento e instrumentação padronizados. Os dentes foram divididos aleatoriamente de acordo com a técnica de obturação: G1 - Condensação lateral e vertical a frio, G2 - Termoplástica (E \& Q Plus) e G3 - Cone único, grupos-controle negativo e positivo, e obturados com o mesmo cimento (AH-Plus);. Os dentes foram montados em um modelo de dupla câmara, onde a infiltração de Enterococus faecalis foi avaliada por um período de 30 dias pelo teste de turbidez de EVA. Resultados: Os resultados foram estatisticamente tabulados e analisados pelos teste Exato de Fisher e Kruskal-Wallis, usando-se o programa BioEstat 3.0 onde se revelou não haver diferença estatística significante entre os grupos experimentais G1, G2 e G3, quando as técnicas foram avaliadas separadamente ou entre os grupos. Não houve diferença entre as técnicas avaliadas quando utilizado o cimento AH-Plus.
\end{abstract}

DESCRITORES: Endodontia - Obturação do canal radicular - Infiltração Dentária.

\section{ABSTRACT}

Intrduction: Taking into consideration that the sealing of the canal system is a decisive factor for the success of endodontic therapy, this study ains to evaluate the microleakage in filled teeth with three obturation techniques: lateral and vertical condensation of cold, the continuoes wave condensation heat (E \& Q Plus) and single cone system (ProTaper Universal@). Methods: Forty-eight teeth had their length and standard instrumentation. The teeth were randomly divided according to the technique of closure: G1 - Cold lateral and vertical condensation, G2 - Thermoplasticized (E \& Q Plus) and G3 - Single cone, with the same sealer (AH-Plus); and control groups negative and positive. The teeth were mounted on a model of dual chamber where the infiltration of Enterococus faecalis was evaluated for a period of 30 days by testing the turbidity of EVA. Results: The results were statistical tabulated and analysised by Fisher Exact test and Kruskal-Wallis using the program BioEstat where 3.0 showed no statistically significant difference between the experimental groups G1, G2 and G3, when the techniques were evaluated separately or between groups. There was no difference between the techniques evaluated when the AH-Plus cement was used.

DESCRIPTORS: Endodontics - Root canal obturation - Dental leakage.

\footnotetext{
* Especialista em Endodontia pela Universidade Cidade de São Paulo - UNICID/São Paulo (diego_ito@ibest.com.br)

** Mestre e Doutor em Endodontia pela Universidade de São Paulo - USP/São Paulo

*** Mestre e Doutor em Endodontia pela Universidade de São Paulo - USP - São Paulo

**** Mestre em Endodontia pela Universidade de São Paulo - USP/São Paulo
} 


\section{N T RO DUÇ ÃO}

A Odontologia passa por um momento de mudanças marcantes e irreversíveis na sua história. Nunca as reabilitações da função mastigatória e estética foram tão abordadas e discutidas como hoje com as técnicas e tecnologias dos implantes osteointegrados. Todo tipo de informação chega à população de maneira rápida, e esta vem à procura do Cirurgião-dentista em busca dessas informações, procurando reabilitar, de maneira satisfatória, o apareIho estomatognático.

Concomitante a toda essa inovação, outras áreas da Odontologia também vêm sofrendo um processo de inovação, inclusive nas técnicas de obturação endodôntica, possibilitando a solução de patologias e preservando o elemento dental muitas vezes condenado erroneamente.

Diante da constante evolução, é de fundamental importância para o Cirurgiãodentista a atualização, a seleção e o domínio de técnicas que possibilitem restabelecer as funções do elemento dental de maneira satisfatória, reduzindo a probabilidade de re-intervenções e aumentando as chances de sucesso.

A Endodontia praticamente se baseia no controle ou manutenção da sanificação do conduto radicular. A polpa, talvez a única estrutura capaz de um combate primário a qualquer microrganismo presente na flora bucal, é extirpada ou encontra-se num processo decomposto ou de decomposição quando é iniciada a terapia endodôntica.

A obturação do canal radicular completa as três fases principais da terapia endodôntica: abertura coronária, sanificaçãomodelagem e selamento endodôntico. Assim reforça o conceito da importância de se eliminarem espaços vazios no interior dele. Todas as fases que antecedem a obturação, como preparo químico-mecânico, por exemplo, assim como o selamento coronário que se segue posteriormente à obturação, são responsáveis pelo sucesso da obturação e do tratamento endodôntico como um todo.

Desse modo, fica implícita a importância de se eliminarem espaços vazios que possam perpetuar ou iniciar um processo
ISSN 1983-5183

infeccioso, originando patologias de causa endodôntica.

\section{REVISÃO DA LITERATURA}

\section{Aspectos Gerais}

Acredita-se que, de todos os insucessos da terapia endodôntica, a falha no processo de obturação corresponda a $60 \%$ dos casos (Ingle', 1962).

A condensação lateral é uma técnica relativamente simples de ser realizada, pois necessita de um cone principal que deve ser travado no limite apical do preparo. Após a confirmação do travamento, os espaços são preenchidos com cones secundários com o auxílio de espaçadores digitais compatíveis com o diâmetro do canal, que são inseridos a $3 \mathrm{~mm}$ aquém do limite de preparo compactando o material previamente inserido. Os cones são inseridos até que se preencham os espaços vazios do conduto.

Ainda no processo de obturação, os cones principais estão sendo industrializados com variações também em sua conicidade, copiando a conicidade dos instrumentos de níquel-titânio, de modo que no momento da obturação seja utilizado apenas um único cone de guta-percha principal por canal, não sendo necessária a realização da condensação lateral, facilitando e diminuindo o tempo de obturação. Uma das marcas conhecidas é o sistema Protaper Universal ${ }^{\circledR}$ (Dentsply, Maillefer) em que os cones são padronizados de acordo com os últimos instrumentos de acabamento. (Figura1).

Sabendo-se que o ideal da obturação seria o preenchimento do sistema de canais com o maior volume possível de material sólido, Schilder ${ }^{2}$, em 1967, apresentou a técnica de obturação de canais radiculares com o emprego da gutapercha aquecida, a qual, acreditava-se, oferecia um melhor selamento apical em razão de uma melhor adaptação e do meIhor preenchimento do sistema de canais, que era comprovado radiograficamente pela obturação de múltiplas ramificações laterais e forames apicais. Utilizando esse conceito, varias técnicas foram introduzidas no mercado.

Em 1973, Grossman ${ }^{3}$ propôs que a função da obturação radicular é selar o con-
ITO DL

SHIMABUKO DM

AUN CA

$B R U M T B$

AVALIAÇÃO DA INFILTRAÇÃO

BACTERIANA EM

tÉCNICAS DE

obtuRaÇão Do

CANAL RADICULAR

199

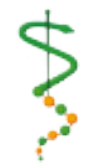

REVISTA DE ODONTOLOGIA DA UNIVERS I DADE CIDADE DE SÃO PAULO

$2010 ; 22(3): 198-$ 215, SET-DEZ 


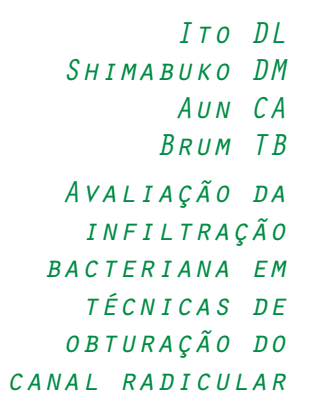

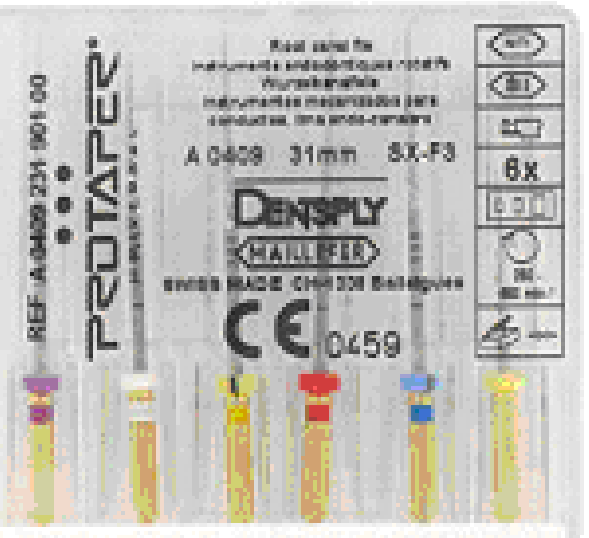

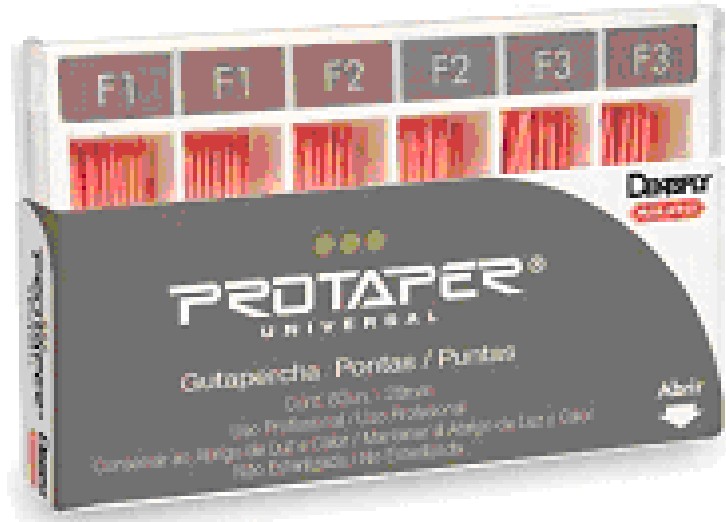

Figura 1: Sistema rotatório de Níquel-Titânio PróTaper Universal à esquerda; Cones padronizados de acordo com os últimos instrumentos à direita.

duto hermeticamente e eliminar toda via de acesso aos tecidos do periápice.

A partir dos trabalhos de Yee et al. ${ }^{4}$, 1977, Torabinejad et al. ${ }^{5}$, 1978, e Marlin et al. ${ }^{6}, 1981$, a Meta Dental Corporation lançou um sistema injetável e guta-percha denominado E \& Q Plus (Figura 2).

É um aparelho que conta com um sistema duplo. Em uma extremidade, uma seringa é utilizada para injetar a guta-percha termoplastificada no interior do canal radicular. Na outra extremidade, baseado num sistema desenvolvido por Buchanam ${ }^{7}$ em 1996, há uma unidade formadora de calor, em formato de caneta, que apreende uma ponta condensadora (Figura 3) que quando inserida no canal radicular juntamente com um cone de guta-percha termoplastificavel (Figura 4), plastifica-a e a condensa permitindo a realização da técnica "Onda contínua de Condensação". A grande vantagem desse sistema é a possibilidade do aquecimento e condensação da guta-percha no terço apical, o que teoricamente

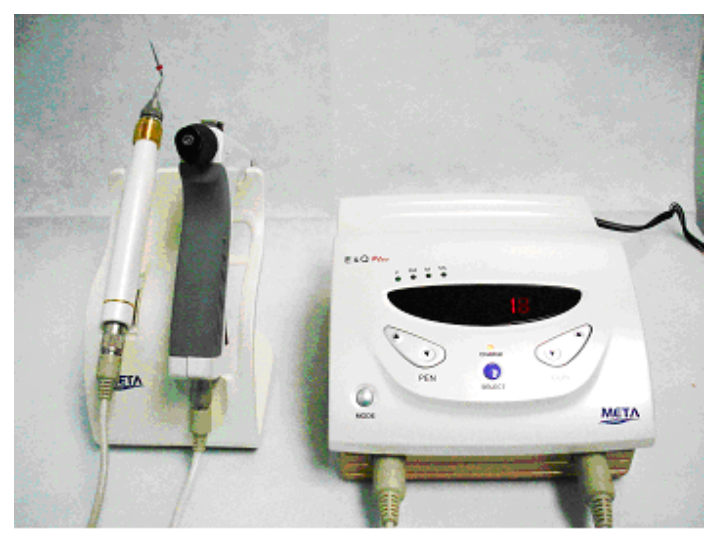

Figura 2: Aparelho E\&Q Plus. No suporte à esquerda, calcador elétrico e pistola de injeção de guta-percha; resultaria num melhor selamento apical, e o selamento de canais laterais.

A pistola de guta-percha, também fabricada por outras companhias, (as modificações são poucas mas a ideia principal é a mesma), o Obtura II, fabricado pela Unitek Corporation, é um exemplo. Assim como o condensador elétrico, que é conhecido como Touch'n Heat e System B, ambos realizam a técnica de onda contínua de condensação.

A guta-percha tem sido aceita como o melhor material obturador para tratamento endodôntico (Paiva e Antoniazzi ${ }^{8}$, 1991) e considerado o material de escolha pela maioria dos cirurgiões-dentistas. Desde sua introdução na endodontia, esse material é utilizado de diferentes formas, sendo a mais utilizada a forma de cones padronizados, que são introduzidos no interior do canal e condensados lateral e verticalmente, conjuntamente a um cimento obturador.

A obturação do canal radicular é de fundamental importância durante o tratamento endodôntico, pois, através de um correto vedamento do sistema de canais radiculares, é mantida a desinfecção atingida durante a limpeza e modelagem do canal, minimizando a recontaminação e consequente insucesso da terapia endodôntica. Todos os espaços do canal preparado devem ser preenchidos, evitando-se, assim, possível recontaminação. Foi verificada, em tubos de dentina, implantados em tecido conjuntivo, reação inflamatória intensa quando havia espaços vazios de 4 a $8 \mathrm{~mm}$. Esses locais podem ser preenchidos por microrganismos e líquidos tecidu- 


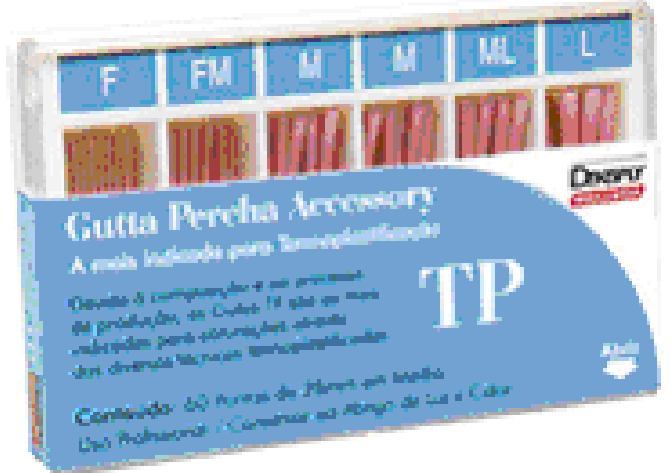

Figura 3: Guta-percha termoplástica

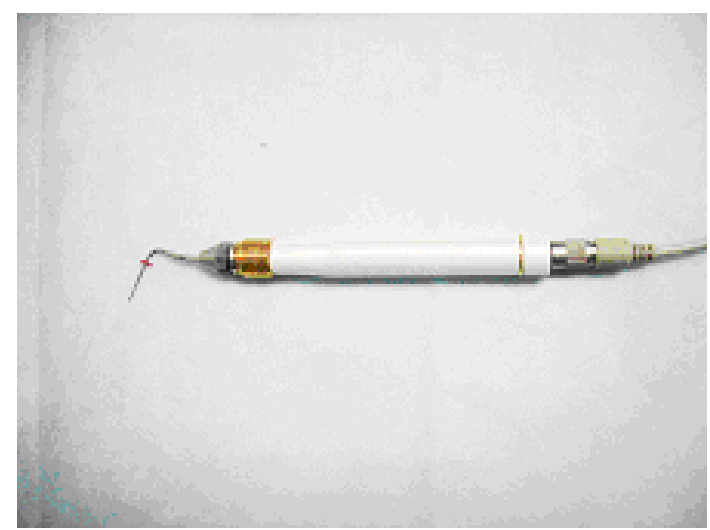

Figura 4: Calcador elétrico

ais e representar agentes irritantes aos tecidos periapicais (Cohen e Burns ${ }^{9}$, 2000).

A obturação do canal radicular corresponde à fase final do tratamento endodôntico e expressa a qualidade deste por meio do simples aspecto radiográfico, que, embora de caráter limitado, constitui o único recurso disponível para o momento (Estrela e Figueiredo ${ }^{10}, 2001$ ).

Falhas durante o processo de obturação são os maiores responsáveis pelo fracasso no tratamento endodôntico (Nair ${ }^{11}$, 2006).

\section{Aspectos Microbiológicos}

O amplo contato com o meio bucal e a presença de grandes lesões cariosas talvez justifiquem a presença de bactérias em lesões periapicais, entretanto a presença de bactérias também é observada em dentes tratados endodonticamente. Hancock III et al. ${ }^{12}$, em 2001, avaliando casos de insucesso na população norte-americana, coletaram utilizando pontas de papel absorventes, microrganismos presentes em lesões radiolúcidas de dentes tratados endodonticamente. Esses microrganismos foram cultivados de forma aeróbica e estritamente anaeróbica. A flora microbiológica era predominantemente de organismos gram-positivos, onde o Enterococcus faecalis foi o mais comumente encontrado.

Segundo Siqueira et al. ${ }^{13}$ (2002), evidências indicam que as doenças perirradiculares são desordens infecciosas. A questão não é o quão amplo os microrganismos estão envolvidos na patogenia das desordens, mas o quanto específicos eles são. A lista de microrganismos envolvidos continua expandindo, a cada ano surgem novos trabalhos com novas espécies e métodos moleculares têm contribuído significamente para o conhecimento sobre os microorganismos envolvidos.

Ainda em 2002, Siqueira et al. ${ }^{14}$ num estudo utilizando microscópio eletrônico de varredura, observaram em dentes com extensas lesões cariosas extraídos com suas respectivas lesões perirradiculares aderidas, a presença de bactérias em todo o sistema de canais e em profundidade nos túbulos dentinários. A prevalência era de bactérias do tipo coccus, ou bacilos formando comunidades mistas. Espiroquetas foram observados solitariamente ou eventualmente com outras formas bacteroides. Apesar de variados, inclusive com a presença de fungos, esses microrganismos aparentavam viver em colônias em ambiente conjugado.

O Enterococcus faecalis é um microrganismo comumente encontrado no trato gastro-intestinal de seres humanos e não tem uma participação ativa em processos cariosos ou periodontais na cavidade oral. Entretanto, é o microrganismo mais comumente encontrado em leões perirradiculares assintomáticas de origem endodôntica. Os processos infecciosos perirradiculares apresentam uma grande variedade de microrganismos. Estudos utilizando PCR (Cadeia de reação Polimerase) indicam o Enterococcus faecalis relacionado a tratamentos endodônticos insatisfatórios e abcessos crônicos. Esses estudos utilizam métodos genéticos moleculares para a identificação de microrganismos. São métodos confiáveis, em que se compara a cadeia genética do microrganismo com outro semelhante de um banco pré-existente.(Rôças et al. ${ }^{15}$ 2004).
ITO DL

SHIMABUKO DM

AUN CA

BRUM TB

AVALIAÇÃO DA

INFILTRAÇÃO

BACTERIANA EM

TÉCNICAS DE

obTURAÇÃO DO

CANAL RADICULAR

$\therefore 201$

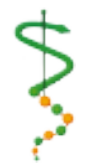

REVISTA DE

ODONTOLOGIA DA

UN I VERS I DADE

Cidade de São

PAULO

$2010 ; 22(3): 198-$

215, SET-DEZ 
ITO $D L$

SHIMABUKO DM

$A \cup N \quad C A$

$B R \cup M T B$

AVALIAÇÃO DA

INFILTRAÇÃO

BACTERIANA EM

TÉCNICAS DE

OBTURAÇÃO DO

CANAL RADICULAR

\section{2}

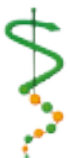

REVISTA DE

ODONTOLOGIA DA

UNI VERSIDADE

CIDADE DE SÃO

PAULO

$2010 ; 22(3): 198-$

215, SET-DEZ
Conclusão semelhante foi citada por Nair ${ }^{11}$ em 2006, que, numa revisão literária sobre as causas da Periodontite Apical Crônica persistente, e entre elas, a de origem microbiana, descreveu a flora microbiana de insucessos endodônticos com base em diversos trabalhos. Foi concluído que os microrganismos mais frequentemente isolados são do gênero Actinomyces, e bactérias do gênero Enterococcus e Propionibacterium, ou seja, predominantemente gram-positivos. Semelhantemente, ela cita o Enterococcus faecalis como o microrganismo mais frequentemente reportado com prevalência de $22 \%$ a $77 \%$ dos casos analisados, sendo a segunda porcentagem oriunda de estudos genéticos moleculares.

\section{Cimento Endodôntico}

Os cimentos endodônticos podem ser avaliados em diversas categorias, como escoamento, resistência, biocompatibilidade e inibição de crescimento bacteriano, por exemplo. Mas basicamente os métodos que utilizam a incidência de fluidos são de grande interesse para a endodontia, e dentro desse aspecto, podem ser divididos em biológicos e não biológicos.

Miletic et al. ${ }^{16,17}$ publicaram trabalhos semelhantes em 1999 e em 2002. Foi utilizado um modelo de transporte de fluido, não biológico todos os dentes foram obturados com guta-percha e mantidos em solução salina fisiológica a $37^{\circ} \mathrm{C}$ por 2 semanas no primeiro trabalho (1999) e por 1 ano no segundo trabalho (2002), onde se observava a movimentação de uma pequena bolha de ar num tubo capilar de vidro. Concluiu-se que os cimentos KetacEndo e AH-plus demonstraram menos infiltração quando comparados aos outros cimentos estudados. No mesmo ano de 2002, Miletic et al. ${ }^{18}$ voltaram a avaliar cimentos, agora com uma variedade menor e de mesmo tipo, AH26 e AH-Plus, ou seja, cimentos resinosos. Os microrganismos utilizados foram Streptococcus mutans, Streptococcus mitis, Prevotella melaninogenica e Lactobacilus acidophilus em conjunto numa mesma cultura e Cândida albicans numa cultura separada. Concluiu-se que não houve diferença estatística entre os grupos avaliados.
Utilizando uma metodologia diferente, biológica, Timpawat et al. ${ }^{19}$, em 2001, avaliaram a infiltração de Enterococcus faecalis em dentes utilizando três cimentos de diferentes composições: AH-Plus (base de resina epóxica), Apexit (Hidróxido de Cálcio) e Ketac-Endo (Ionômero de Vidro). Conclui-se que o cimento resinoso $(\mathrm{AH}-$ Plus) foi menos suscetível que o cimento de Hidróxido de Cálcio, quando a infiltração coronária bacteriana foi estudada.

Cobankara et al. ${ }^{20}$ em 2002 utilizaram o método de infiltração fluida para avaliar quatro cimentos diferentes: AH-Plus, Ketac-Endo e dois cimentos de composições diferentes das citadas como o RoekoSeal à base de silicone (polidimetilsiloxano) e Sultan à base de óxido de zinco. O cimento mais infiltrado foi o Sultan. AH-Plus e Ketac-Endo não tiveram diferença estatística e se comportaram de maneira semeIhante mas não superior ao RoekoSeal.

Gomes et al. ${ }^{21}$ em 2004 analisaram as propriedades antimicrobianas de cinco cimentos endodônticos: Endo Fill, Endomethasone, Endomethasone N, Sealer 26 e AH-Plus, em diferentes períodos pósmanipulação, sendo eles imediatamente e após 24 horas, 48 horas e 7 dias, sendo submetidos à infiltração dos seguintes microrganismos: Cândida albicans, Staphylococcus aureus, Enterococus faecalis, Streptococcus sanguis e Actinomyces naeslundii, através do crescimento microbiano em meio líquido e teste de difusão em agar. Concluiu-se que, após a manipulação, Endo Fill e Endomethasone apresentavam a maior atividade antimicrobiana, sem diferença estatística entre eles. Sealer ${ }^{26}$ teve a menor atividade microbiana. Nos outros tempos não houve diferença estatística entre os cimentos.

No ano de 2005, Orstavik ${ }^{22}$ publicou uma revisão literária sobre materiais utilizados na obturação radicular, visando os aspectos técnicos, biológicos e testes clínicos. Além dos materiais de preenchimento que já se utilizaram como os cones de prata, ainda se utiliza a gutta-percha como principal material obturador. $\mathrm{O}$ autor se atém principalmente aos tipos de cimentos e às propriedades de um cimento ideal propostas por Grossman ${ }^{3}$ em 1978. Inclusive são descritas as marcas mais uti- 
lizadas e suas respectivas composições. Todos os tipos de estudos laboratoriais comparativos, biológicos e técnicos são mencionados. A importância e a variedade dos testes clínicos in vivo também. Foi concluído que os cimentos à base de óxido de zinco e eugenol e os de resina epóxica demonstram, ao longo do tempo, resultados bons clinica e laboratorialmente.

Foi avaliado em 2006, por Cobankara et al. ${ }^{23}$, o selamento apical dos cimentos Rocanal 2, Sealapex, AH-Plus e RC Sealer. Os dados foram coletados aos 7, 14 e 21 dias. Ao final do estudo conclui-se que o melhor selamento foi obtido pelo Sealapex, não havendo diferença estatística entre os outros cimentos avaliados.

A absorção e a solubilidade de três cimentos resinosos à base de metacrilato (EndoREZ, Epiphany e InnoEndo) foram estudadas por Donnely et al. ${ }^{24}, 2007$. Como comparativos, eles utilizaram cimentos diferentes: Kerr EWT e Ketac-Endo (controles positivos), GuttaFlow e AHPlus (controles negativos). Os resultados demonstraram que a absorção foi variada entre todos os cimentos comparados: Epiphany $(8 \%)$, Ketac-Endo (6.2\%), InnoEndo (3,4\%), EndoREZ (3,0\%), AH-Plus (1,1\%), GuttaFlow $(0,4 \%)$ e Kerr EWT $(0,3 \%)$. Significantemente a maior solubilidade $(3,5 \%$ a $4 \%)$ foi observada nos cimentos resinosos e no Kerr EWT (3,95\%), quando comparados com Ketac-Endo (1,6\%), AHPlus $(0.16 \%)$ e GuttaFlow $(0,13 \%)$. A Associação Dental Americana (ADA) requer uma solubilidade menor que $3 \%$ para os cimentos endodônticos. Somente KetacEndo, AH-Plus e Gutta-Flow alcançaram esse critério.

Em 2007, Eudeniz et al. ${ }^{25}$ avaliaram a citotoxidade de cinco novos cimentos endodônticos: RC sealer, Epiphany, EndoREZ, GuttaFlow e Acroseal; comparando-os com três cimentos já existentes: AH-Plus, RoekoSeal e Apexit, utilizando fibroblastos gengivais primários humanos (HGF) e uma linhagem de fibroblastos de rato (L929). Todos os cimentos foram montados em blocos de Teflon cilíndricos. Foram montados dois grupos com os respectivos tipos celulares, sendo o HGF cultivado em placa Petri, em condições ideais de temperatura e umidade, e L929 a frescos, ambos mantidos por 7 dias antes da extração. Os resultados demonstraram que os cimentos resinosos (Epiphany e EndoREZ) e os de hidróxido de Cálcio (Apexit e Acroseal) foram significantemente mais citotóxicos que os outros cimentos $(\mathrm{p}<0.05)$. Entretanto as células do tipo L929 foram mais sensíveis ao Apexit e o EndoREZ que as do tipo HGF. O AH-Plus não exerceu nenhum efeito citotóxico sobre nenhum dos tipos celulares, inclusive induzindo proliferação celular nas células do tipo L929.

Baumgartner et al. ${ }^{26}$ em 2007 compararam pré-molares inferiores obturados com gutta-percha e cimento AH-Plus, com cones e cimento resinosos do sistema Resilon/Epiphany, ambos pela técnica de condensação por onda contínua. Os espécimes foram submetidos à infiltração bacteriana de Enterococcus faecalis por um período de 50 dias. Através da curva de Kaplan-Meyer, a associação gutta-percha/AH-Plus demonstrou uma tendência melhor na prevenção da infiltração quando comparada com Resilon/Epiphany. O que não foi significantemente comprovado quando comparados estatisticamente. Com um tempo médio de infiltração de 35 dias para gutta-percha/AH-Plus e de 33 dias para Resilon/Epiphany conclui-se que há limitações nesse estudo, mas não há uma vantagem aparente em se utilizar o conjunto Resilon/Epiphany sobre guttapercha/AH-Plus.

Metodologias utilizadas na avaliação da obturação endodôntica

Em 1989, já se discutia a validade das metodologias empregadas na avaliação de tratamentos endodônticos, Kersten e Moorer $^{27}$; Campos e Pashey ${ }^{28} 2003$ publicaram, nesse ano, um estudo em que compararam tipos diferentes de obturações com diferentes metodologias. Os autores se indagavam como diversos estudos laboratoriais utilizando corantes, ou seja, substâncias com relativo pequeno tamanho molecular, apresentavam uma alta incidência de infiltração, quando comparadas com alto sucesso da terapia endodôntica. Era sabido que somente a infiltração de agentes de tamanho molecular maior como microrganismos ou alto peso
ITO DL

SHIMABUKO DM

AUN CA

BRUM TB

AVALIAÇÃO DA INFILTRAÇÃO

BACTERIANA EM

TÉCNICAS DE

obTURAÇÃO DO

CANAL RADICULAR

$\therefore 203$

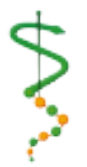

REVISTA DE

ODONTOLOGIA DA

UNIVERS I DADE

CIDADE DE SÃO

PAULO

$2010 ; 22(3): 198-$

215, SET-DEZ 
ITO $D L$

SHIMABUKO DM

$A \cup N C A$

$B R \cup M T B$

AVALIAÇÃO DA

INFILTRAÇÃO

BACTERIANA EM

TÉCNICAS DE

OBTURAÇÃO DO

CANAL RADICULAR

\section{4}

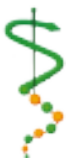

REVISTA DE

ODONTOLOGIA DA

UNI VERS I DADE

CIDADE DE SÃO

PAULO

$2010 ; 22(3): 198-$

215, SET-DEZ molecular como produtos bacterianos, eram os causadores das doenças periapicais. O objetivo dos autores era primeiramente avaliar como diversos tipos de obturação poderiam prevenir a infiltração de partículas de tamanho bacteriano e de grandes moléculas de proteína, e posteriormente avaliar a infiltração do corante azul de metileno, um indicador comumente utilizado, quando comparado com produtos bacterianos de considerável patogenicidade.

Todos os dentes tiveram suas coroas seccionadas e sua instrumentação padronizada. A obturação foi realizada com um cone único de gutta-percha, com e sem condensação vertical e um mesmo cimento (AH-26). Utilizaram-se soluções em suspensão de azul de metileno, de gotículas de látex, compatíveis com o tamanho de um organismo Streptococcus, endotoxinas de E. coli lipopolissacarídeos e o Ácido butírico que é um metabólito de microrganismos e tóxico aos tecidos. Os resultados demonstraram resultados próximos, entretanto superiores aos do azul de metileno em comparação ao Ácido Butírico e ambos distantes inferiormente das outras soluções. Os autores concluíram que testes qualitativos e quantitativos de infiltração utilizando moléculas de baixo peso molecular podem ter significância duvidosa para a prática endodôntica e sozinhas, incertas para provocar doenças periapicais. Entretanto, a micro infiltração de grandes moléculas de substâncias antígenas tóxicas ou bactérias nos tecidos periapicais é um importante fator.

Wu e Wesselink ${ }^{29}$, em 1993, realizaram uma revisão com base em diversos estudos de infiltração em tratamentos endodônticos publicados nos anos de 1980 a 1990, levando em consideração a metodologia, aplicação e relevância. Os autores mencionam que no ano de 1990, a cada 4.3 artigos científicos publicados nos principais periódicos endodônticos, 1 utilizava como metodologia a infiltração endodôntica. O método mais comumente utlilizado foi a mensuração linear da penetração (corante ou radioisótopo) ao longo do selamento endodôntico. Na maioria dos estudos avaliando técnicas obturadoras, a condensação lateral a frio foi a mais utilizada como controle para comparação. Segundos os autores, os resultados desses trabalhos são questionáveis principalmente por não haver uma padronização na metodologia.

Barthel et al. ${ }^{30}$, em 1999, compararam a infiltração bacteriana contra a infiltração de corantes por meio de sistema de dupla câmara, variando os tipos de cimento utlilizados, sendo eles: Ketac Endo, AH26 e Roth's 801 Sealer. Após a instrumentação e obturação, os elementos foram submetidos à infiltração de Staphylococcus epidermidis por um período de 38 dias. $\mathrm{Na}$ avaliação bacteriana, não houve diferença estatística entre os cimentos avaliados. Já na avaliação por corantes o cimento AH26 apresentou maior infiltração. Entretanto, os autores não observaram correlação entre os dois tipos de avaliação e acreditam que o tamanho da molécula do agente penetrante não é um parâmetro relevante para determinar um apropriado teste para avaliar o selamento endodôntico.

Dulac et al. ${ }^{31}$ avaliaram, em 1999, utilizando blocos pré-fabricados de resina (com canais simulados) seis tipos de técnicas de obturação do canal radicular: condensação lateral a frio, onda contínua de condensação, condensação vertical com calor, carregador com guta-percha termoplastificada (Thermafil), condensação lateral com calor e condensação vertical em alta temperatura (Obtura II). Após a obturação de todos os grupos, observou-se que todas as técnicas obturaram os canais laterais com cimento, independente do terço em que se encontravam. Condensação vertical com calor, carregador com guta-percha termoplastificada (Thermafil) e onda contínua de condensação obturaram os canais laterais com guta-percha significamente melhor do que quando o cimento foi utilizado. As técnicas de obturação de onda contínua de condensação e carregador com guta-percha termoplastificada (Thermafil) obturaram significamente melhor os canais laterais do terço apical do que as outras técnicas comparadas.

Siqueira et al. ${ }^{32}$ avaliaram, em 2000, três técnicas de obturação submetidas à infiltração de saliva humana coletada pela equipe do experimento e trocada a cada 
três dias. Ele comparou, por 60 dias, as técnicas de condensação lateral, carregador com guta percha termoplastificada (Thermafil) e onda contínua de condensação também ultilizando o sistema de dupla câmara. A instrumentação e o cimento (Fill canal) foram padronizados. Ao final do experimento o autor não observou diferença estatística entre as técnicas avaliadas e concluiu que nenhuma delas foi capaz de prevenir a infiltração coronária de saliva humana.

Nelson et al. ${ }^{33}$, em 2000, utilizando blocos com canais simulados, compararam as técnicas de condensação lateral a frio e condensação lateral aquecida, em duas etapas (condensações) utilizando o sistema System B com baixo aquecimento $\left(101^{\circ} \mathrm{C}\right)$. Os canais artificiais foram preparados com instrumentação rotatória e em seguida obturados sem a utilização de cimento. Os resultados mostraram que a condensação lateral aquecida trouxe um acréscimo significante na densidade por peso quando comparada com a condensação lateral a frio. Os dados foram analisados e comparados, concluindo-se que a condensação lateral aquecida, utilizando o System B, resultou numa maior densidade por peso quando comparada com a condensação lateral a frio.

Pommel e Camps ${ }^{34}$ avaliaram em 2001 a infiltração apical de raízes obturadas com System B, técnica de cone único, condensação vertical a frio, condensação lateral a frio e Thermafil utilizando o mesmo cimento (Sealite). Após 30 dias verificou-se que System B, Thermafil e condensação vertical apresentaram uma menor infiltração em relação às outras duas técnicas: condensação lateral produziu moderada infiltração apical, entretanto a técnica de cone único demonstrou alta infiltração.

Goldberg et al. ${ }^{35}$ em 2001 compararam a condensação lateral a frio com outras cinco técnicas de obturação termoplatificáveis: técnica híbrida, Ultrafil, Obtura II, System B + Obtura II e Thermafil. Após a avaliação radiográfica observou-se que um grande número de canais laterais foram obturados pelas técnicas Ultrafil, Thermafil, System B + Obturall, quando comparadas com as outras técnicas, sepa- rando as técnicas em dois grupos amplificados: o de grande quantidade de canais laterais obturados e o de baixa quantidade de canais laterais obturados, não havendo diferença estatística entre as técnicas de cada grupo.

De Moor e Hommez ${ }^{36}$ avaliaram em 2002 a infiltração coronária e apical do corante Índia após um variado tempo de teste. As técnicas avaliadas eram a condensação lateral a frio, condensação vertical ao calor, técnica híbrida, Thermafil e SoftCore. Todas utilizando como cimento o AH26. Foram selecionados dentes unirradiculares com o ápice formado. As infiltrações ocorreram independente da técnica com aumento das infiltrações após os 4 meses. Ao final do experimento concluiu-se que a técnica híbrida apresentou os melhores resultados. Thermafil apresentou infiltração coronária maior nos 4 meses quando comparada com outras técnicas e o sistema Soft-Core apresentou os piores resultados, não apresentando diferença estatística quando comparado com Thermafil.

Akisue $^{37}$ em 2003 avaliou a capacidade de selamento apical do sistema termoplástico de obturação por ondas contínuas de condensação (System B). Para isso, os espécimes foram divididos em 2 grupos experimentais: G1-obturados pela condensação lateral; G2-obturados pelo System B. Utilizou-se a endotoxina pura de E. coli como marcador na infiltração no sentido ápico-cervical. O autor concluiu que o Grupo G2 (System B) apresentou os melhores resultados, com média de infiltração da endotoxina de 0,28432 UE/ml, contra $0,36825 \mathrm{UE} / \mathrm{ml}$ dos espécimes obturados pela técnica de condensação lateral (G1) sendo essa diferença significante ao nível de 5\%.

Kardon et al. ${ }^{38}$ em 2003 fizeram comparações utilizando um modelo de fluido sob pressão, onde a infiltração também era medida através da movimentação de uma bolha de ar em uma micropipeta. Os dentes foram separados em três grupos mais os grupos de controle (dois). No primeiro grupo denominado $A$, os dentes eram obturados pela técnica de cone único e cimento EndoRez. No segundo grupo, B, os dentes foram obturados também com
ITO $D L$

SHIMABUKO DM

AUN CA

$B R \cup M T B$

AVALIAÇÃO DA

INFILTRAÇÃO

BACTERIANA EM

TÉCNICAS DE

obTURAÇÃo DO

canal RADICULAR

$\therefore 205$

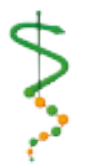

REVISTA DE

ODONTOLOGIA DA

UN I VERS I DADE

Cidade de São

PAULO

2010; 22(3): $198-$

215, SET-DEZ 
ITO $D L$

SHIMABUKO DM

$A \cup N C A$

$B R \cup M T B$

AVALIAÇÃO DA

INFILTRAÇÃO

BACTERIANA EM

TÉCNICAS DE

OBTURAÇÃO DO

CANAL RADICULAR

\section{6}

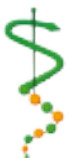

REVISTA DE

ODONTOLOGIA DA

UNI VERS I DADE

CIDADE DE SÃO

PAULO

$2010 ; 22(3): 198-$

215, SET-DEZ cone único e o cimento utilizado foi o AH-Plus. No terceiro grupo, C, os elementos foram obturados pela técnica de condensação vertical aquecida, utilizando-se a associação dos sistemas System B mais Obtura II, e também utilizando-se o cimento AH-Plus. Os resultados demonstraram que o Grupo A apresentou significante maior infiltração quando comparado com outros grupos, que não apresentaram diferença estatística entre si. Ao final do experimento os autores seccionaram uma amostra dos elementos infiltrados do Grupo A e analisaram em microscópio eletrônico de varredura em diversas magnificações e foi observada uma má adaptação do cimento tanto nas paredes dentinárias como no cone de guta percha. O cimento apresentava uma aparência porosa, semeIhante a uma "esponja", sugerindo uma degradação pela umidade.

Monticelli et al. ${ }^{39}$, em 2007, avaliaram, através de um sistema de dupla câmara, a infiltração bacteriana de $S$. mutans em três técnicas de obturação: condensação vertical aquecida (sistema System B e Obtura II) com cimento AH-Plus, cone único e cimento à base de ionomêro de vidro Activ GP e cone único com cimento Gutta-Flow. O grupo de condensação vertical aquecida não apresentou infiltração durante os primeiros dois meses, sendo o menos infiltrado de todos os grupos, concluindo-se que os outros dois grupos não conseguiram impedir a infiltração bacteriana.

Horsted-Bindslev et al. ${ }^{40}$ em 2007 avaliaram radiograficamente as técnicas de condensação lateral e cone único utilizando o cimento AH-Plus. Os elementos utilizados foram molares tanto superiores quanto inferiores, que eram instrumentados e obturados segundo as duas técnicas e radiografados pelas projeções mésio/ distal, vestíbulo/lingual ou vestíbulo/palatina. Em seguida foram avaliados por quatro examinadores que classificaram as obturações como "suficiente" ou "insuficiente" de acordo com os respectivos canais: mesial, distal e palatino. Uma quantidade relativa de canais considerados suficientes nas projeções vestíbulo/ lingual, foram considerados inadequados nas projeções mesio/distal, principalmente em canais distais de molares inferiores, sugerindo que a técnica de condensação lateral pode ser mais adequada em certos tipos de canais, principalmente em canais ovais.

Da Silva Neto et al. ${ }^{41}$ avaliou em 2007 a técnica de cone único variando quatro cimento à base de resina: $\mathrm{AH}-26$, AH-Plus, EndoRez e um cimento experimental denominado MBP, desenvolvido na Faculdade de Odontologia de Bauru (FOB-USP) que, além de resina, possuía na sua formulação hidróxido de cálcio. Os cimentos AH-Plus e MBP foram os que apresentaram os melhores resultados quando comparados ao AH26 e EndoRez.

Brosco et al. ${ }^{42}$ publicaram em 2008 um trabalho que avaliou a infiltração de Enterococcus faecalis, num modelo de dupla câmara, quatro diferentes técnicas de obturação: condensação lateral a frio, Microseal, Touch'n Heat + Ultrafil e a técnica híbrida de Tagger. Ao final do experimento concluiu-se que a técnica híbrida de Tagger produziu um grande número de infiltrações quando comparada com as outras técnicas. Não houve diferença estatística entre as outras técnicas.

Sendo assim, fica evidente que o estudo tanto de cimentos, quanto de técnicas de obturação, se baseia principalmente na infiltração de substâncias contaminadas ou não. Apesar da variedade de metodologias, todas elas visam avaliar eventuais falhas no processo de obturação, ou seja, problemas oriundos da adaptação entre os materiais ou parede dentinária.

\section{PROPOS I ÇÃO}

Diante do exposto, é objetivo desta pesquisa avaliar a infiltração bacteriana de Enterococus faecalis, por um período total de 30 dias, em três técnicas de obturação do canal radicular: condensação lateral e vertical a frio, cone único e termoplastificada.

\section{MATERIAL E MÉTODOS}

Após a aprovação pelo Comitê de Ética da Universidade Cidade de São Paulo, 48 pré-molares inferiores foram selecionados a partir de um montante doado pelo Banco de Dentes da Universidade Cidade de 
São Paulo.

Todos os elementos eram mantidos em ambiente úmido a $37^{\circ} \mathrm{C}$. Todo o tecido adjacente à raiz foi removido com uma cureta periodontal universal. Foram radiografados com incidência vestíbulo/ lingual e mesio/distal, sendo descartados aqueles que possuíam mais de um canal radicular, curvaturas acentuadas, nódulos pulpares, calcificações e ápices incompletos. Em seguida seus comprimentos foram mensurados através de um paquímetro Mitutoyo $\AA$, após uma média aritmética se estabeleceu um comprimento de $20 \mathrm{~mm}$ para todos os elementos. Essa medida foi transferida para os elementos através de um Compasso de Willis e os dentes foram seccionados com discos diamantados de Carburundum montados em mandril e contra-ângulo (exceto Grupo G4- controle negativo) para que se chegasse à medida estabelecida, de modo que só foram selecionados aqueles que sofreram a secção no terço médio da coroa.

Nos elementos que não apresentavam sua câmara pulpar exposta foi realizada a cirurgia de acesso com uma broca tipo Carbide \#700XXL, naqueles que apresentavam exposição da câmara, o orifício foi ampliado com broca tronco-cônica de ponta inativa Endo-Z®. Com a câmara pulpar preenchida com Hipoclorito de Sódio a $1 \%$, foi realizado o preparo das entradas dos canais com broca de Broca de Largo e Gates-Glidden \#2 nos terços cervical e médio, respectivamente.

Foi realizada a penetração desinfetante com farta irrigação e aspiração, utilizando-se uma lima manual do tipo $K \# 10$, $21 \mathrm{~mm}$. O comprimento real de trabalho (CRT) foi estabelecido quando a ponta do instrumento surgia no forame apical, recuava-se $1 \mathrm{~mm}$, então era fixado o CRT. Todos os elementos apresentavam $19 \mathrm{~mm}$ como CRT.

Com a câmara e a entrada do conduto radicular preenchidas com gel de Endo PTC, era obtida uma efervescência resultante da reação do gel em contato com algumas gotas de hipoclorito de sódio. $\mathrm{Na}$ presença dessa efervescência, que durava cerca de dois minutos, os dentes foram instrumentados manualmente com limas do tipo $K \# 15$, \#20 e \#25, sequencialmen- te, todas com $21 \mathrm{~mm}$ de comprimento, seguidas por instrumentos rotatórios S1, S2, F1, F2 e F3 de níckel-titânio marca Prota-

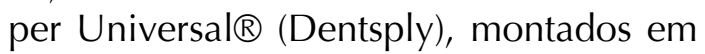
motor endodôntico X-Smart ${ }^{\circledR}$ respeitando-se o CRT. Toda vez que se trocava um instrumento ou cessava a efervescência na cavidade, o conduto era irrigado com $8 \mathrm{ml}$ de hipoclorito de sódio a 1\%, montado em seringa plástica e cânula para irrigação calibrada em $16 \mathrm{~mm}$, ou seja, a 3 mm do CRT. Então uma nova porção de gel de Endo PTC era novamente reposta e reagida, só então se continuava o preparo. O preparo apical foi realizado com um instrumento manual do tipo $\mathrm{K} \# 40$, onde o limite era alcançado e o instrumento rotacionado com um quarto de volta no sentido horário e um quarto no sentido anti-horário, até não se encontrar mais resistência no interior do canal. Para a remoção de smear layer o canal foi irrigado com $8 \mathrm{ml}$ de ácido cítrico a 15\% seguido por $8 \mathrm{ml}$ de hipoclorito de sódio a 1\%.

Todos os elementos foram mantidos em ambiente úmido em tubos de vidro do tipo penicilina e encaminhados para a esterilização a calor úmido em autoclave a $121^{\circ}$ Celsius pelo tempo de 15 minutos. Posteriormente foram separados aleatoriamente em 5 grupos, sendo 3 grupos de 14 elementos cada (G1, G2, G3), e 2 gruposcontrole de 3 elementos cada (G+ e G-) e encaminhados para a obturação.

Em ambiente asséptico, sobre um campo estéril, utilizando-se gaze de algodão, instrumental e luvas estéreis, iniciou-se a obturação pelo Grupo G1. Todos os grupos seguiram as mesmas normas de biosegurança, onde os elementos eram manipulados envoltos por uma gaze estéril assim como na instrumentação e os cones de guta-percha previamente desinfetados em hipoclorito de sódio a $1 \%$ por $30 \mathrm{mi}-$ nutos.

No Grupo G1, um cone principal de guta-percha apreendido por uma pinça do tipo Perry foi previamente padronizado com régua calibradora em $0,40 \mathrm{~mm}$ no seu diâmetro inicial, e em seguida inserido no interior do canal, sendo posteriormente avaliado no teste visual para comprovar seu comprimento e no teste táctil para comprovar seu travamento. O conduto foi seco
ITO DL

SHIMABUKO DM

AUN CA

$B R \cup M T B$

AVALIAÇÃO DA

INFILTRAÇÃO

BACTERIANA EM

TÉCNICAS DE

obTURAÇÃo Do

CANAL RADICULAR

$\therefore 207$

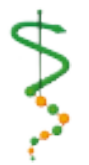

REVISTA DE

ODONTOLOGIA DA

UN I VERS I DADE

Cidade de São

PAULO

$2010 ; 22(3)$ : $198-$

215, SET-DEZ 
ITO $D L$

SHIMABUKO DM

$A \cup N \quad C A$

$B R \cup M \quad T B$

AVALIAÇÃO DA

INFI LTRAÇÃO

BACTERIANA EM

TÉCNICAS DE

OBTURAÇÃO DO

CANAL RADICULAR

\section{8}

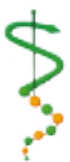

REVISTA DE

ODONTOLOGIA DA

UNI VERS I DADE

CIDADE DE SÃO

PAULO

$2010 ; 22(3): 198-$

215, SET-DEZ com pontas de papel absorvente estéril, padronizadas em comprimento e calibre de acordo com o instrumento do preparo apical e o cimento endodôntico AH-Plus ${ }^{\circledR}$ manipulado de acordo com as recomendações do fabricante. O cone principal selecionado anteriormente era impregnado com o cimento e o mesmo inserido no canal com movimentos de pincelamento, de modo que toda a parede do canal fosse preenchida com cimento e o cone travado no limite. O conduto era preenchido com cones secundários do tipo FF envoltos por cimento, seguidos por cones FM. A partir do momento em que a inserção de novos cones tornava-se dificultosa, um espaçador digital tamanho C, pré-calibrado em 16 mm e também impregnado com cimento endodôntico, era inserido vagarosamente, com movimentos rotacionais de um quarto de volta, entre a parede do canal e os Cones já inseridos, até o limite determinado no instrumento. Os mesmos eram então condensados lateralmente, o instrumento removido e um novo cone acessório inserido no espaço obtido.Todo o processo foi repetido até que não se conseguisse inserir mais cones acessórios.

Um calcador do tipo Paiva $n^{\circ} 3$ era aquecido ao rubro e os cones cortados $2 \mathrm{~mm}$ abaixo da abertura coronária. Então um novo calcador do mesmo tipo em temperatura ambiente compactava o material verticalmente, realizando a condensação vertical.

No Grupo G2, cones do tipo TP, tamanho FM, previamente desinfetados e também padronizados em relação ao seu comprimento e diâmetro, sofreram avaliação nos testes táctil e visual. Os cones foram então reservados e com o auxílio de uma lâmina de bisturi estéril $\mathrm{n}^{\circ} 15$, sobre uma placa de vidro polida estéril, os cones eram incisados $2 \mathrm{~mm}$ aquém de sua ponta. Essa pequena incisão era feita de forma suave, sem pressão, de forma que a lâmina penetrasse até a metade da secção transversal do cone, permitindo que esse trecho de $2 \mathrm{~mm}$ não se destacasse nem deformasse em relação ao resto do cone. O mesmo era novamente reservado. Após a secagem do conduto, o cimento era manipulado e inserido nas paredes do canal com um cone de papel absorvente. O cone semisseccio- nado era então impregnado com cimento e inserido no canal. Num único movimento de pressão apical e rotação horária, o trecho semisseccionado era separado do resto do cone, ficando fixado no limite do CRT. Para confirmação do procedimento, o restante do cone removido era avaliado visualmente com o auxílio de uma régua endodôntica, comprovando a redução em seu comprimento. Um aparelho para obturação termoplastificada E \& Q se encontrava ligado e preparado, seu calcador elétrico foi montado com uma ponteira na cor azul (\#30), calibrada em 17 mm no seu comprimento. Após o aquecimento a $120^{\circ} \mathrm{C}$ alertado pelo sinal sonoro do equipamento, o instrumento era inserido no interior do canal com uma leve compressão até o limite predeterminado, aguardava-se o resfriamento por um tempo de 10 segundos e, num movimento único, no sentido lateral e coronário, era removido do interior do canal. O outro instrumento do aparelho E \& Q, uma pistola para injeção de gutapercha termoplastificada em bastão, que já se encontrava aquecida e reservada, foi utilizada para inserir a guta-percha aquecida em pequenos incrementos, que eram compactados com o calcador elétrico em temperatura ambiente. Esse processo foi repetido até que todo o conduto fosse preenchido até $2 \mathrm{~mm}$ abaixo do nível da coroa e compactado verticalmente com o auxílio de um calcador em temperatura ambiente.

No Grupo G3, cones de guta-percha da marca PróTaper Universal ${ }^{\circledR}$ tamanho F3 foram previamente desinfetados e padronizados em régua calibradora no seu diâmetro inicial em 0,40 mm. Em seguida os cones eram avaliados nos testes visual e táctil, confirmando-se seu comprimento no CRT e seu travamento. Os cones foram reservados e, após a secagem do conduto com pontas de papel absorvente, eram impregnados com cimento e então inseridos no interior do canal radicular com movimentos de pincelamento, preenchendo-se todas paredes, sendo finalmente travado. Um calcador do tipo Paiva \#3 era então aquecido ao rubro e o cone era cortado $2 \mathrm{~mm}$ abaixo da linha da coroa. Depois, compactado verticalmente com o auxílio de um calcador em temperatura ambiente.

Os três elementos do Grupo G4-Con- 
trole Positivo não sofreram qualquer tipo de obturação, sendo somente instrumentados do mesmo modo que os grupos avaliados e os três elementos do Grupo G5Controle Negativo não sofreram qualquer tipo de intervenção com relação à abertura, instrumentação e obturação.

Inicialmente, todos os elementos tiveram suas raízes impermeabilizadas com resina epóxica Arauldite 24 horas ${ }^{\circledR}$, os $3 \mathrm{~mm}$ finais da raiz não eram impermeabilizados, exceto o Grupo G5-Controle negativo, no qual toda a raiz era impermeabilizada. A câmara superior era formada pela inserção das coroas dos espécimes previamente impermeabilizados em um tubo do tipo Eppendorf que tinha sua base seccionada por um disco diamantado, montado em mandril e contra-ângulo. Os espécimes eram adaptados de modo que o limite do tubo coincidisse com o limite amelo-dentinário do dente, só então uma nova camada de resina epóxica era inserida, selando a união dente/tubo. Após se-

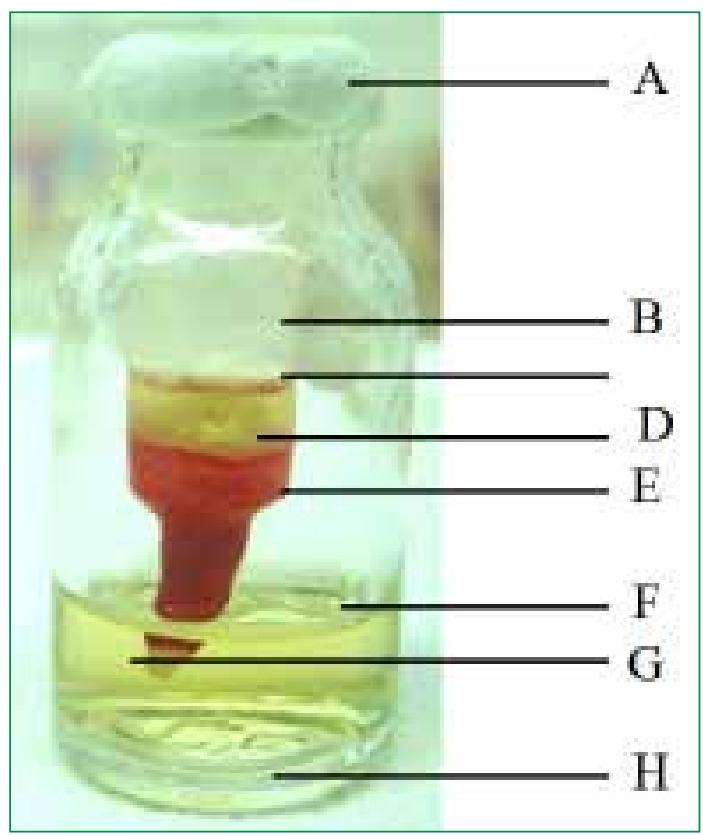

Figura 5: (A) Silicone pesado vedando a interface tubo/vidro. (B) Tubo Eppendorf (câmara superior). (C) Inóculo de microrganismos. (D) Entrada cervical do canal. (E) Interface tubo/raiz selada com Super-Bonder ${ }^{\circledR}$ em gel e duas camadas de esmalte de unha. (F) Meio de cultura esterilizado. (G) Superfície apical sem vedamento. (H) Vidro de penicilina (câmara inferior cagem, todo o conjunto era selado com esmalte sintético na cor vermelha, também respeitando os $3 \mathrm{~mm}$ finais da raiz, exceto Grupo G5-Controle Negativo, em que toda sua raiz foi impermeabilizada.

Todos os conjuntos foram embalados em pacotes futuramente selados, identificados, e enviados para radiação Gama (Cobalto 60) com dose entre 22 e 25 KGy no Centro de Tecnologia das Radiações (CTR - IPEN), de onde retornaram de forma íntegra e etiquetados com marcadores de esterilização. Logo após, o conjunto tubo eppendorf-raiz (câmara superior) era posicionado em um recipiente de vidro (câmara inferior), previamente esterilizado em autoclave, contendo $4 \mathrm{~mL}$ de EVA para todos os grupos. A interface entre o tubo e o vidro foi vedada com silicone pesado, para evitar a evaporação do caldo na câmara inferior e possível contaminação (Figura 5)

Toda manipulação microbiológica foi realizada sob câmara de fluxo laminar desinfetada com álcool $70 \%$ e ação de luz ultravioleta durante $5 \mathrm{~min}$. Também foram utilizados campos de TNT esterilizados, luvas e ponteiras esterilizadas.

Um volume de $100 \mu \mathrm{L}$ de Enterococcus faecalis ATCC29212, mantido em estoque a $-20^{\circ} \mathrm{C}$, foi inoculado em $3 \mathrm{~mL}$ de EVA previamente esterilizado e mantido durante 18 horas a $37^{\circ} \mathrm{C}$ em estufa de cultura. Após o crescimento, a suspensão foi padronizada com auxílio da escala dois de McFarland, correspondendo a aproximadamente $6 \times 10$ bactérias por $\mathrm{mL}$.

A seguir o tubo era agitado por 30 segundos em vortex e uma alíquota de $50 \mu \mathrm{L}$ da cultura era introduzida dentro do tubo eppendorf (câmara superior), nos espécimes dos Grupos G1 a G4 e ainda nos controles positivo e negativo. Uma alíquota de $250 \mu \mathrm{L}$ de caldo EVA esterilizado era depositada na câmara superior. A cada três dias o caldo EVA da câmara superior era renovado, removendo-se $250 \mu \mathrm{L}$ da cultura já presente e adicionando-se 250 $\mu \mathrm{L}$ de EVA esterilizado.

Diariamente, durante 30 dias, todos os espécimes foram cuidadosamente agitados, e verificava-se a turvação ou não na câmara inferior. Caso houvesse turvação, indicando a infiltração bacteriana, o espé-
ITO $D L$

SHIMABUKO DM

$A \cup N C A$

BRUM TB

AVALIAÇÃO DA

INFILTRAÇÃO

BACTERIANA EM

TÉCNICAS DE

obtuRaÇão Do

CANAL RADICULAR

209

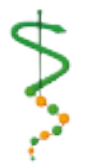

REVISTA DE

ODONTOLOGIA DA

UN I VERS I DADE

Cidade de São

PAULO

$2010 ; 22(3)$ : $198-$

215, SET-DEZ 


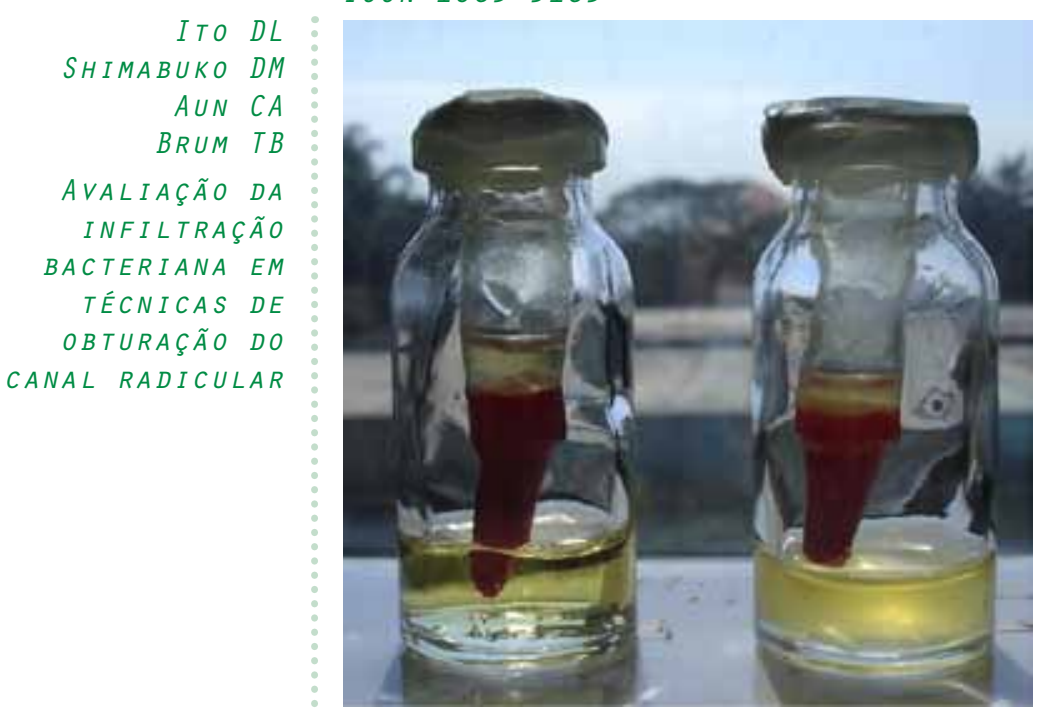

Figura 6: Espécime não infiltrado comparado com espécime com infiltração.

cime era automaticamente separado dos demais e uma alíquota de $10 \mu \mathrm{L}$ da câmara inferior era semeada em uma placa de Petri contendo TSA. As placas eram incubadas durante 24 horas a $37^{\circ} \mathrm{C}$. Após esse período, eram fixadas e coradas através da coloração de gram, sendo então observadas as características morfotintoriais das colônias em microscópio óptico (X1000). Após os 30 dias, ou seja, ao final do experimento, uma amostra da câmara superior de todos os grupos foi semeada em placas de TSA para comprovação da viabilidade dos microrganismos na câmara até o final do ensaio.

\section{RESULTADOS}

A Figura 6 exemplifica a turvação ob- servada quando a infiltração ocorria.

No controle positivo, todos os espécimes sofreram infiltração no primeiro dia. O controle negativo não apresentou infiltração e a viabilidade do inóculo foi comprovada, após o período experimental (30 dias).

No $30^{\circ}$ dia de experimento, dez amostras (três para cada grupo experimental e uma para o grupo-controle negativo) das câmaras superiores foram colhidas aleatoriamente e semeadas em placas TSA, comprovando-se a viabilidade dos inóculos durante o experimento. Em todos os espécimes que apresentaram turvação, $\mathrm{O}$ microrganismo encontrado era idêntico ao inoculado inicialmente. Em todos os espécimes infiltrados por E. faecalis, a observação das lâminas revelou características morfotintoriais semelhantes às apresentadas no início do experimento.

Os dados de cada grupo foram cruzados entre si e a análise estatística utilizou o teste Exato de Ficher e Kruskal-Wallis no programa Biostat 3.0.

Utilizando-se o teste não-paramétrico bilateral de Exato de Fisher entre os grupos, não houve diferença estatística significante $(P>0,05)$, o que mostra não haver diferença entre as técnicas obturadoras diante da infiltração de $E$. faecalis.

O teste de variância para amostragem não-normal de Kruskal-Wallis $(p<0,05)$ sobre os dias corridos por todos os espécimes até a infiltração demonstrou não haver diferença estatística entre os grupos avaliados, tanto nas interações entre gru-

Tabela 1: Os espécimes identificados em azul são os infiltrados ao longo dos 30 dias.

\begin{tabular}{|c|c|c|c|c|c|c|}
\hline CV e L & * Dias Corridos & TP & * Dias Corridos & Con U & $*$ & Dias Corridos \\
\hline I & & I & & I & & \\
\hline II & & II & & II & & \\
\hline III & & III & & III & & \\
\hline VI & & VI & & VI & & \\
\hline V & & V & & V & & 22 \\
\hline VI & & $\mathrm{VI}$ & & $\mathrm{VI}$ & & \\
\hline VII & & VII & & VII & & 23 \\
\hline VIII & & VIII & & VIII & & \\
\hline IX & & IX & & IX & & \\
\hline$x$ & & $x$ & & $x$ & & \\
\hline XI & & XI & & XI & & \\
\hline XII & & XII & & XII & & \\
\hline XIII & & XIII & & XIII & & \\
\hline XIV & & XIV & & XIV & & \\
\hline
\end{tabular}


Tabela 2: Espécimes infiltrados ao final do experimento

\begin{tabular}{cccc}
\hline Grupo & Espécimes Infiltrados & Espécimes não infiltrados & Porcentagem infiltrados \\
\hline G1 (CV e L) & 0 & 14 & $0 \%$ \\
G2 ( TP) & 0 & 14 & $0 \%$ \\
G3 (ConU) & 2 & 12 & $4,76190 \%$ \\
Total & 2 & 40 & $4,76190 \%$ \\
\hline \hline
\end{tabular}

pos como entre todos os grupos.

A Tabela 1 demonstra os espécimes infiltrados e os dias corridos.

A Tabela 2 demonstra os espécimes infiltrados ao final do experimento:

Após 30 dias não houve diferença estatística entre os grupos estudados.

\section{I SCUSSÃO}

A prevenção da infiltração marginal após o processo de obturação constitui um fator primordial para a manutenção da sanificação obtida depois do preparo químico-cirúrgico do canal radicular. Deve-se promover o melhor vedamento possível, por meio do correto selamento do conduto e da correta restauração do elemento dental.

Outro fator importante é a presença de smear layer conhecida por alterar a propriedade seladora dos cimentos. Utilizamos, neste experimento, o ácido cítrico a 15\% com a intenção de se remover o magma dentinário. Como comprovado por Clark Holke et al. ${ }^{43}$ (2003) e Cobankara et al. ${ }^{44}$ (2004) a presença de smear layer influencia na infiltração marginal.

As metodologias utilizadas ao longo do tempo tentam demonstrar, in vitro, situações semelhantes o mais possível com a realidade, sendo o emprego de corantes frequentemente utilizados para se verificar e quantificar a infiltração tanto apical quanto coronária. Entretanto, esse método é muito questionado, principalmente por se tratar de uma substância de moléculas com relativo menor tamanho molecular do que as bactérias ou seus derivados que causam os problemas oriundos da infiltração do tratamento endodôntico. Portanto, a utilização de bactérias representa uma semelhança maior com as realidades clínicas e passa a ser alternativa interessante para o estudo da infiltração marginal (Kersten e Moorer ${ }^{27}$, 1989).

Foram utilizados neste trabalho as bac- térias Enteroccus faecalis, pois estas podem fazer parte da flora bucal e são frequentemente encontradas em infecções juntamente com outros microrganismos aeróbios e anaeróbios facultativos, e são predominantes em casos refratários com lesões assintomáticas (Timpawat et al. ${ }^{19}$, 2001; Hancock III et al. ${ }^{12}$ 2001; Rôças et al. ${ }^{15} 2004$ e Nair ${ }^{11}$ 2006).

Toda a manipulação dos espécimes foi realizada de maneira asséptica, em ambiente de fluxo laminar com o propósito de prevenir possíveis contaminações das amostras e a ocorrência de falsos resultados. Todos o procedimentos de esterilização anteriores à manipulação visaram à inexistência de bactérias no conjunto experimental. Os tubos de vidro foram esterilizados em autoclave a $134^{\circ} \mathrm{C}$ por um período de 15 minutos, assim como todo o instrumental utilizado durante a manipulação dos espécimes. Todos os espécimes foram autoclavados antes da etapa do preparo químico-cirúrgico e irradiados em raio Gama (Cobalto 60) com dose entre 22 e 25 KGy no Centro de Tecnologia das Radiações (CTR - IPEN), após montagem na câmara superior (vide anexo).

A câmara superior tinha uma quantidade do seu total $(250 \mu \mathrm{L})$ trocada a cada três dias, a fim de se manter a curva de crescimento bacteriano e uma quantidade relativa de microrganismo na câmara superior (padronizada com auxílio da escala 2 de McFarland, correspondendo a aproximadamente $6 \times 10^{8}$ bactérias por $\mathrm{mL}$ ). No caso de infiltração, o espécime era separado e uma amostra da câmara inferior era cultivada em placa Petri, coletada e fixada em lâminas e coradas com coloração de Gram, e se observava em microscópios as características morfotintoriais do $E$. faecalis.

Um ponto interessante a se discutir neste estudo foi a padronização dos espécimes. Todos os elementos pertenciam
ITO $D L$

SHIMABUKO DM

AUN CA

$B R U M T B$

AVALIAÇÃO DA INFILTRAÇÃO

BACTERIANA EM

tÉCNICAS DE

obtuRaÇão do

canal RADICULAR

211

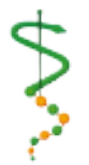

REVISTA DE

ODONTOLOGIA DA

UN I VERS I DADE

Cidade de São

PAULO

$2010 ; 22(3): 198-$

215, SET-DEZ 
ISSN 1983-5183

ITO DL

SHIMABUKO DM

$A \cup N C A$

$B R \cup M \quad T B$

AVALIAÇÃO DA

INFI LTRAÇÃO

BACTERIANA EM

TÉCNICAS DE

OBTURAÇÃO DO

CANAL RADICULAR

$212 \ldots$

REVISTA DE

ODONTOLOGIA DA

UNIVERSIDADE

CIDADE DE SÃO

PAULO

2010; 22(3): $198-$

215, SET-DEZ al. $\left.{ }^{29}, 1993\right)$. Camps $^{34}$ 2001). outras técnicas. a um mesmo grupamento dentário (prémolares inferiores), previamente radiografados, sem curvaturas ou canais duplos, com ápice formado e com tamanho médio prestabelecido antes mesmo da definição do comprimento real e do trabalho ser fixado, ou seja, todos os dentes possuíam o mesmo comprimento total e a mesma altura da cavidade coronária. O que se verificou importante em outro estudo (Wu et

A fim de se prevenir a infiltração, técnicas de obturação termoplastificada surgiram com o objetivo de melhorar o vedamento do sistema de canais radiculares entre elas Schilder, Obtura II, Ultrafil, Thermafil, McSpadden, Touch'n Heat, System B e E \& Q Plus.

Como a mais recente técnica promissora, Buchanan 7 , em 1996, desenvolveu um aparato constituído de uma unidade geradora de calor que, através de um cabo, o conduz para uma ponta condensadora, e, quando levado ao interior do canal, esta plastifica e condensa ao mesmo tempo o cone de guta-percha. Essa técnica denominada de onda contínua de condensação permite o selamento de canais laterais, e na região apical possibilita melhor adaptação do material obturador à parede dentinária, permitindo um melhor selamento, como comprovado em outros estudos (Dulac et al. ${ }^{31}$ 1999; Nelson et al. ${ }^{33}$ 2000; Goldberg et al. ${ }^{35} 2001$ e Pommel e

O grupo obturado pela técnica de cone único apresentou infiltração ao longo dos 30 dias. Tempo mais rápido do que comparado com outros trabalhos que utilizavam outras metodologias de infiltração (Da Silva Neto et al. ${ }^{41}, 2007$ ), o que talvez poderia sugerir que a metodologia utilizando microrganismos semelhantes aos patógenos encontrados na cavidade oral seja mais adequada do que comparada a

O sucesso da impermeabilização da superfície radicular foi realizado com uma camada de resina epóxica de (Araldite $24 \mathrm{hs} \circledast$ ) e comprovado pela ausência de infiltração bacteriana no Grupo-Controle Negativo após o período experimental de 120 dias. Contrariamente, houve rápida infiltração no período de 24 horas nos espécimes do Grupo-Controle Positivo, mostrando-se que a não obturação resulta na rápida infiltração do conduto radicular.

O sistema de dupla câmara utilizado neste estudo (câmara superior + dente + câmara inferior) foi baseado nos modelos de Timpawat et al. ${ }^{19}$ (2001), Gilbert et al. ${ }^{45}$ (2001), Miletic et al. ${ }^{17}$ (2002), Akissue ${ }^{37}$ (2003) e Shipper e Trope ${ }^{46}$ (2004), onde todos os modelos possuíam uma câmara contendo o agente contaminante e uma câmara contendo substrato estéril, ambas separadas pela amostra a ser analisada.

Os resultados deste estudo vêm ao encontro do trabalho de Rôças et al. ${ }^{15}$ (2004) e Nair ${ }^{11}$ (2006), que confirmaram a capacidade da bactéria $E$. faecalis de penetrar em canais radiculares obturados, comprovando mais uma vez a importância do adequado selamento do sistema de canais radiculares para a obtenção do êxito do tratamento endodôntico.

Como análise geral dos resultados encontrados neste estudo, verificou-se a necessidade do aperfeiçoamento desse método e sua comparação com os demais anteriormente empregados. Mesmo sendo de alta complexidade, o intuito seria de se obter uma metodologia capaz de reproduzir as complexas condições in vivo, produzindo, assim, uma confiabilidade ainda maior nos estudos de percolação marginal, alcançando-se, assim desse modo, o objetivo maior que é a obtenção de materiais e técnicas que possibilitem o correto e absoluto vedamento do forame apical, prevenindo a infiltração de exsudato inflamatório bem como microrganismos e seus subprodutos.

\section{CONCLUSÃO}

De posse dos resultados obtidos, podese concluir que, mediante um correto preparo químico-cirúrgico em que se obtenham uma boa desinfecção, modelagem e remoção de smear layer, as técnicas de obturação, condensação vertical e lateral a frio, termoplastificada e cone único quando utilizadas com o cimento resinoso AH-plus - não diferem qualitativamente, quando submetidas à infiltração bacteriana coronária. 
1. Ingle Jl. Éxitos e fracasos en endodoncía. Rev Asoc Odontol Argent. 1962; 50(2): 67.

2. Schilder HC. Filling root canals in three dimensions. Dent Clin North Am. 1967 Nov; 723-44.

3. Grossman LI. Prática Endodóntica. $3^{\mathrm{a} e d}$. Buenos Aires: Mundi., 1973. 407p.

4. Yee FS, Marlin J, Krakow AA, Gron P. Three dimensional obturation of the root canal using injection-molded thermoplasticized dental gutta-percha. J Endod. 1977 May; 3(5): 168-74.

5. Torabinejad M, Skobe Z, Trombly PL, Krakow AA, Gron P, Marlin J. Scanning electron microscopic study of root canal obturation using thermoplasticized gutta-percha. J Endod. 1978 Aug; 4(8): 245-50.

6. Marlin J, Krakow AA, Desilets RP, Gron P. Clinical of injection molded thermoplsticized gutta-percha. J Endod. 1981 Jun;7(6):277-81.

7. Buchanan LS. The continuous wave obturation technique: centered condeation of warm gutta-percha in 12 seconds. Dent Today. 1996 Jan; 15(1): 60-2.

8. Paiva JG, Antoniazzi JH. Endodontia: bases para prática clínica. $2^{\mathrm{a}}$ ed. São Paulo: Artes Médicas; 1991.

9. Cohen S, Burns RC. Caminhos da Polpa. $7^{a}$ ed. Guanabara Koogan, Rio de Janeiro, 2000. 838 p.

10. Estrela C, \& Figueiredo, JAP. Endodontia: princípios biológicos e mecânicos. $1^{\mathrm{a}}$ ed. Artes Médicas, São Paulo, 2001.819p.

11. Nair PN. On the causes of persistent apical periodontitis: a review. Int Endod. J. 2006 Apr; 39(3): 249-81.

12. Hancock III HH, Sigurdsson A, Trope M, Moiseiwitsch J, Hill C. Bacteria isolated after unsuccessful endodontic treatment in a North American population. Oral Surg Oral Med Oral Pathol. 2001 May; 91(5): 579-85.

13. Siqueira Jr JF, Roças IN, Lopez HP. Patterns of microbial colonization in primary root canal infections. Oral Surg Oral Med Oral Pathol Oral Radiol Endont. 2002 Feb; 93(2):174-8.

14. Siqueira Jr JF. Endodontic infections: concepts, paradigms, and perspectives. Oral Surg Oral Med Oral Pathol Oral Radiol Endont. 2002 Sep; 94(3): 281-93.

15. Rôças IN, Siqueira Jr JF, Santos KRN. Association of Enterococus faecalis with different forms of periradicular diseases. J Endod. 2004 May; 30(5): 315-20.

16. Miletic I, Anic I, Pezelj-Ribaric S, Jukic S. Leakage of five root canal sealers. Int Endo J. 1999 Sep; 32(5): 415-18.

17. Miletic I, Anic I, Pezelj-Ribaric S, Jukic S, Karlovic Z, Bosnjak A. Apical leakage of five root canal sealers after one year of storage J Endod. 2002 Jun; 28(6): 431-2.

18. Miletic I, Prpic-Mehicic G, Marsan T, Tambic-Andrasevic A, Plesko S, Karlovic Z, Anic I. Bacterial and fungal microleakage of AH26 and AH-Pus root canal sealers. Int Endo J. 2002 May; 35(5): 428-32.

19. Timpawat S, Amornchat C, Trisuwan WR. Bacterial coronal leakage after obturation with three root canal sealers. J Endod. 2001 Jan; 27(1): 36-9.

20. Cobankara FK, Adanir N, Belli S, Pashley DH. A quantitative evaluation of apical leakage of four root canal sealers. Int Endo J. 2002 Dec; 35(12):979-84.

$B R \cup M \quad T B$

AVALIAÇÃO DA INFILTRAÇÃO

BACTERIANA EM

tÉCNICAS DE

obTURAÇÃO DO

CANAL RADICULAR

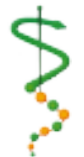

REVISTA DE ODONTOLOGIA DA UNIVERSI DADE Cidade de São PAULO 
ITO $D L$

SHIMABUKO DM :

$A \cup N \quad C A$

$B R \cup M T B$

$A \vee A L I A C ̧ \tilde{A} O \quad D A$

INFI LTRAÇÃO

BACTERIANA EM

TÉCNICAS DE

OBTURAÇÃO DO

CANAL RADICULAR

\section{4}

REVISTA DE ODONTOLOGIA DA UNIVERSIDADE CIDADE DE SÃO PAULO 2010; 22(3): 198215, SET-DEZ
21. Gomes BPFA, Pedroso JA, Jacinto RC. In vitro evaluation of the antimicribial activity of five root canal sealers. Braz Dent J. 2004; 15(1): 30-35.

22. Orstavik D. Materials used for root canal obturation: technical, biological and clinical testing. Endo Topics. 2005;12:28-38.

23. Cobankara FK, Orucoglu H, Sengun A, Belli S. The quantitative evaluation of apical sealing of four endodontic sealers. J Endod. 2006 Jan; 32(1): 66-8.

24. Donnelly A, Sword J, Nishitani Y, Yoshiyama M, Agee K, Tay FR et al. Water sorption and solubility of methactylate resin-based root canals sealers. J Endod. 2007 Aug; 33(8): 990-4.

25. Eudeniz AU, Mustafa K, Dahl JE. Cytotoxicity of new resin, calcium hydroxide and silicon based root canal sealers on fibroblasts derived from human gingiva and L929 cell lines. Int Endo J. 2007 May; 40(5): 329-7.

26. Baumgartner G, Zebnder M, Paque F. Enterococcus faecalis type starin leakage through root canals filled with gutta-percha/AH-Plus or Resilon/Epiphany. J Endod. 2007 Jan;33(1):45-47.

27. Kersten HW, Moorer WR. Particles and molecules in endodontic leakage. Int Endod J. 1989 May; 22(3): 118-24.

28. Camps J, Pashley DH. Reliability of the dye penetration studies. J Endod. 2003 Sep; 29(9): 592-4.

29. Wu MK, Wesselink PR. Endodontic leakage studies reconsidered. Part I. Methodology, application and relevance. Int Endod J. 1993 Jan; 26(1): 37-43.

30. Barthel CR, Moshonov J, Shuping G, Orstavik D. Bacterial leakage versus dye leakage in obturated root canals. Int Endod J. 1999 Sep; 32(5): 370-5.

31. Dulac KA, Nielsen CJ, Tomazic TJ, Ferrilho PJ, Hatton JF. Comparison of the obturation of lateral canals by six techniques. J Endod. 1999 May;25(5): 376-80.

32. Siqueira Jr JF, Roças IN, Favieri A, Abad EC, Castro AJR, Gahyva SM. Bacterial leakage in coronally unsealed root canals obturated with 3 different techniques. Oral Surg Oral Med Oral Pathol Oral Radiol Endont. 2000 Nov; 90(5): 647-50.

33. Nelson EA, Liewehr FR, West LA. Increased density of gutta-percha using a controlled heat instrument with lateral condensation. J Endod. 2000 Dec; 26(12): 74850.

34. Pommel L, Camps J. In vitro apical leakage of syetm B compared with other filling Techniques. J Endod 2001 Jul; 27(7): 449-51.

35. Goldeberg F, Artaza LP, De Silvio A. Effectiveness of different obturation techniques in the filling of simulated lateral canal. J Endod 2001 May; 27(5):362-64.

36. De Moor RJG, Hommez GMG. The long-therm sealing ability of an epoxy resin root canal sealer used with five gutta-percha obturation techniques. Int Endo J. 2002 Mar; 35(3): 275-82.

37. Akisue E. Análise in vitro da percolação apical em dentes obturados empregando-se o método e infiltração e quantificação do nível da endotoxina.(Dissertação de mestrado). São Paulo. Faculdade de Odontologia . Universidade de São Paulo. 2003.

38. Kardon BP, Kuttler S, Hardigan P, Dorn SO. An in vitro evaluation of the sealing ability of a new root canal obturation system. J Endod. 2003Oct; 29(10): 658-61.

39. Monticelli F, Sadek FT, Schuster GS, Volkmann KR, Looney SW, Ferrari M et al. Efficacy of two contemporary single-cone filling techniques in preventing bacterial leakage. J Endod. 2007 Mar; 33(3): 310-3. 
40. Horsted-Bindslev P, Andersen MA, Jensen MF, Nilson JH, Wenzel A. Quality of molar root canal fillings performed with the lateral compactation and de single-cone technique. J Endod 2007 Apr ;33(4):468-71.

41. Da Silva Neto U, Moraes GI, Westphalen VPD, Menezes R, Carneiro W, Fariniuki LF. Leakage of four resin-based root canal sealers used with a single-cone technique. Oral Surg Oral Med Oral Pathol. 2007;104:53-57.

42. Brosco VH, Bernadineli N, Torres SA, Consolaro A, Bramante CM, Moraes IG et al. Bacterial leakage in root canals obturated by different techniques. Part 1: microbiologic evaluation. Oral Surg Oral Med Oral Pathol. 2008 Jan; 105(1): 48-53

43. Clark Holke D, Drake D, Walton R, Rivera E. Bacterial penetration through canals of endodontically treated teeth in the presence or absence of the smear layer. J Dent. 2003 May; 31(5): 275-81.

44. Cobankara FK, Adanir N, Belli S, Pashley DH. Evaluation of the influence of smear layer on the apical and coronal sealing ability of two sealers. J Endod. 2004 Jun; 30(6): 406-9

45. Gilbert SD, Witherspoon DE, Berry CW. Coronal leakage followin three obturation techniques. Int Endo J. 2001Jun; 34(4): 293-9.

46. Shipper G, Trope M. In vitro microbial leakage of endodontically treated teeth using new and standar obturation techniques. J Endod. 2004 Mar; 30(3): 154-8.

Recebido em: 19/10/2009

Aceito em: 09/08/2010.

ITO DL

SHIMABUKO DM

$A \cup N C A$

$B R \cup M T B$

AVALIAÇÃo DA

INFILTRAÇÃO

BACTERIANA EM

TÉCNICAS DE

obTURAÇÃo DO

CANAL RADICULAR 